\title{
Entre limitações e superações: as percepções de sujeitos cegos ao viver a cidade
}

\section{Leandro Buzzo Mourão Guimarães Guimarães ${ }^{1}$ and Raul Guimarães ${ }^{2}$}

\begin{abstract}
Contexto: Este artigo tem como objetivo entender como os sentidos do corpo podem se aperfeiçoar de acordo com as condições impostas a cada sujeito. Nesse caso específico, nos interessa compreender como pessoas com limitação visual podem explorar as potencialidades de cada sentido - tato, olfato, paladar, audição para a construção de uma memória espacial e percepção do lugar. Método: Para a realização da pesquisa utilizamos a abordagem qualitativa, além da construção de figuras geoespaciais para dar ênfase aos dados. Resultados: Alem dos sentidos do corpo auxiliar no processo de construção de uma memória espacial, os lugares de pertencimento também constroem esta percepção, pois quanto mais afeto sentimos dos diferentes ambientes, maior a tendência de voltarmos a esse lugar.
\end{abstract}

\section{Keywords}

pessoas cegas, sentidos do corpo, lugar, Presidente Prudente-SP.

\section{Ultrapassando os limites do corpo}

Você já parou para pensar na importância que os sentidos possuem na sua vida? Ouvir uma música de olhos fechados é privilegiar a pureza que a audição pode nos oferecer. Fechar os olhos para beijar quem se ama é privilegiar a pureza que o tato pode nos oferecer. Ao sentir aquele cheirinho de comida de avó, muitas vezes fechamos os olhos resgatando uma memória afetiva, privilegiando a pureza que o olfato pode nos oferecer. Para saber identificar mesmo se gostamos de uma comida muitas vezes fechamos os olhos para tentar valorizar seu sabor, isto é, privilegiar a pureza que o paladar pode nos oferecer.

\footnotetext{
${ }^{1}$ Programa de Pós-graduação em Geografia (PPGG), Universidade Estadual Paulista

${ }^{2}$ Departamento de Geografia, Universidade Estadual Paulista, Presidente Prudente, São Paulo, Brasil

Email: raul.guimaraes@unesp.bre (Raul Guimarães)

Corresponding author:

Leandro Buzzo Mourão Guimarães Guimarães, Programa de Pós-graduação em Geografia (PPGG), Universidade Estadual Paulista

Email: leandro.buzzo@unesp.br
} 
Todos os sentidos contribuem de uma maneira ou outra para nossa construção espacial e localização geográfica, uma geografia construída a partir da exploração dos sentidos do corpo possibilita a apreensão de novos conteúdos geográficos. Os sentidos não só despertam sensações, mas também nos ajudam a construir a percepção de um objeto, um ser ou até mesmo do espaço e lugar, obtendo nossas experiências e formação de uma memória subjetiva.

É evidente que todo sentido sensorial nos desperta algo em nosso cotidiano e viver sem a presença de qualquer um deles é algo que afeta a nossa percepção. Todavia, o objetivo deste artigo é evidenciar as qualidades dos outros sentidos, suas possíveis potencialidades de desenvolvimento e maneira com que podemos ampliar nossa percepção através de corpos ciborgues e até outros elementos vivos valorizando uma geografia da saúde e não uma geografia do sofrimento.

É por isto, que sujeitos com cegueira ganham evidência em nossas análises, uma vez que sem avisão, acabam por desenvolvem ou ampliar as sensações e o sentidos do corpo no espaço geográfico, assim, o artigo tem como objetivo entender como três sujeitos cegos percebem a cidade de Presidente PrudenteSP sem a visão. Este trabalho está vinculado aos resultados da dissertação de mestrado financiada pela Fundação de Amparo à Pesquisa do Estado de São Paulo processo (2018/05967-0).

\section{Os sentidos do corpo na cidade: uma experiência sem a visão}

Para compor a pesquisa utilizamos três sujeitos, dois deles com perda da visão por algum acometimento durante a vida e um deles que já nasceu cego. De acordo com o comitê de ética, seus nomes foram alterados e suas características serão detalhadas a seguir.

\section{Garota Dinamarquesa}

O nome Garota Dinamarquesa foi dado a partir do nome de uma obra literária de David Ebershoff que conta a história do primeiro homem a se submeter a uma cirurgia de mudança de sexo e suas dificuldades enfrentadas a partir desta escolha. A garota dinamarquesa nasceu como Einar Mogens Wegener e, posteriormente à cirurgia, adotou Lili Elbe como nome oficial. História essa, com aspectos semelhantes vivida pelo sujeito da pesquisa. A entrevistada residiu na cidade de São Paulo duas vezes, mas hoje se encontra em Presidente Prudente-SP, 43 anos com perda da visão em 2015.

\section{Dom Quixote de LaMancha}

Seu nome está diretamente ligado ao título do livro "Dom Quixote de la Mancha", a escolha do nome foi pelo caráter desbravador da vida, sempre recheada de muitas histórias e amigos. Dom Quixote nasceu em Estrela do Norte/SP. Cresceu sobre influências rurais, mas também frequentava com bastante intensidade a área urbana de Estrela do Norte/SP e de Presidente Prudente/SP, sua residência atual com seus avós, 33 anos e está sem a visão desde 2011.

\section{Evangelista}

O nome foi dado, principalmente, pelas relações com a igreja evangélica, e pelo fato de que sua vida tem como premissa seguir os ideários protestantes. O forte papel da igreja em sua vida $o$ faz ter posicionamentos contrários com referência as relações entre pessoas do mesmo sexo ou mesmo fazer sexo antes do casamento. Ainda segundo ele, várias vezes considera-se como O Servo de Deus. O sujeito 
da pesquisa já nasceu com cegueira congênita na cidade de São Paulo - SP e se mudou para a cidade de Santo Anastácio-SP ainda muito pequeno residindo ainda hoje neste local, contudo, possui uma relação íntima com Presidente Prudente -SP pelos diversos cursos que realiza, incluindo uma graduação, possui 36 anos, nasceu com ausência de visão.

Estes sujeitos foram protagonistas da pesquisa realizada na cidade de Presidente Prudente -SP, a aplicação metodológica foi pensada para cada sujeito almejando estimular as capacidades desenvolvidas por cada um dos integrantes da pesquisa. Assim as análises e os procedimentos metodológicos serão abordados conjuntamente às análises.

\section{Audição e a linguagem}

Embora algumas pessoas achem monótono ouvir uma pessoa mais velha falando da sua vida, outras pessoas se incomodam em ouvir fofocas! A audição é um elemento essencial em nossas vidas, eu por exemplo, adoro ouvir música, mas poucas vezes fico prestando atenção nos diferentes instrumentos que compõem a música e suas diferentes vibrações.

O fato é que ouvir pode nos trazer diversos elementos para entender as relações sociais e espaciais, suas subjetividades e uma construção mental dos ambientes. Para entender todo esse processo, dialogo neste tópico com Murray Schafer em seu livro "O ouvido pensante", escrito em 1999, o qual nos traz muitos pontos relevantes e nos coloca a pensar sobre tudo o que ouvimos, particularmente os elementos simples, presentes no nosso cotidiano.

É mais interessante ainda que o livro todo está baseado em aula para o primeiro ano de graduação e apresenta os diálogos dessa interação professor - aluno, facilitando no processo de raciocínio.

Segundo o autor, devemos saber distinguir alguns elementos quando falamos sobre ato de ouvir, sendo eles: som, silêncio, ruído, timbre, melodia, amplitude e ritmo. O mais comumente falado por nós é a palavra som, que significa "cortar o silêncio através de uma vibração (SCHAFER, 1999 p.59)", ou então pode ser entendido como "uma linha que se movimenta de modo regular (SCHAFER, 1999 p.59) ". A ausência de som é chamada, portanto, de silêncio, e o ruído é o som indesejável que pode variar de acordo com os sujeitos ou cultura que está inserido (SCHAFER, 1999)

O timbre, por sua vez, é um som que distingue um instrumento de outro, em uma frequência e amplitude. Segundo o autor, o timbre pode ser entendido como a cor do som. A amplitude é a força que vai do mais fraco ao mais forte, do mais grave ao mais agudo. A melodia pode ser qualquer combinação de som, é como o ato de palavras cada letra tem seu som, juntas formam a melodia das palavras. Por fim, o ritmo divide o todo em partes podendo elas ser regulares, irregulares, longas ou breves, um exemplo de marcação de ritmo em nosso cotidiano é o tic-tac do relógio (SCHAFER, 1999).

Todas essas variantes estão presentes de uma forma ou outra em nossas vidas. É evidente que ao perder algum sentido do corpo, nosso cérebro tenta suprir a falta encontrando novas formas de perceber e compreender a realidade. Alguns sujeitos cegos desenvolvem a capacidade distinguir com maior facilidade os sons que estão presentes por não terem a visão. Enfim, enxergar é uma ação socialmente construída pelos seres humanos, e a visão é utilizada, principalmente, como meio de verificação.

Os videntes, quando ouvem algum barulho estranho ou não, rapidamente param para olhar o que está acontecendo. Para quem é cego o som, o tato, olfato e paladar devem oferecer elementos sólidos que ajudam neste processo de verificação da realidade, principalmente quando não é possível utilizar os outros sentidos do corpo. 
Tomemos a batida de carro como, exemplo, com e sem a visão:

I) Sujeitos com capacidade de enxergar: quando você ouve a batida de um carro como exemplo que está relativamente longe e fora do seu campo de visão, qual é a primeira coisa que faz depois de ouvir o som? Certamente é olhar e procurar onde foi a batida para ver se está realmente aconteceu

II) Sujeitos sem a capacidade de enxergar: ao ouvir a batida do carro em uma distância relativamente longe e não tendo a certeza do que aconteceu, certamente começa a ouvir gritos, pessoas correndo, algumas pessoas expressando espanto, e se esperar alguns minutos poderá até ouvir o barulho da ambulância.

O que importa aqui não é quanto tempo demora a identificação da realidade, porque, dependendo do que acontece, os sujeitos com cegueira podem identificar e verificar elementos muitos antes que qualquer pessoa. O fato é que na maioria das vezes ela ocorre com ou sem a visão, pois somos altamente adaptáveis às realidades que nos são expostas, embora alguns (mas) sujeitos mais e outros menos.

As combinações de todos esses elementos integram uma imagem sonora do espaço e produzem uma paisagem. A construção cartográfica a partir do som elucida como os sujeitos com cegueira constroem uma paisagem sonora a partir de um ponto fixo.

O mapa abaixo foi construído a partir de aportes teóricos elucidados na obra de Schafer (1999) e adaptados à realidade da pesquisa. O sujeito participante desta técnica foi Dom Quixote de la Mancha.

Foi solicitado a ele que identificasse e classificasse todos os sons presentes em um espaço público em um tempo de trinta minutos. A partir de sua percepção informou se o som estava perto, médio ou longe.

Por estar em um espaço aberto, houve uma grande diversidade de elementos que ajudaram a compreensão da paisagem. Os sons identificados nas menores distâncias foram o balançar das folhas nas árvores, os pássaros cantando, pessoas conversando ou andando de skate, músicas e toques de celular.

Por estar em uma área verde o barulho dos carros foi ouvido a maior distância, juntamente com mais pássaros cantando e cachorros latindo, além de crianças brincando no parque. Os sons a grande distância

foram ouvidos apenas com a passagem de um helicóptero da polícia e o sino da igreja central, na qual toca de meia em meia hora e pode ser ouvido em grande parte da cidade.

\section{Tato}

O tato é um mecanorreceptor ${ }^{1}$, assim como a audição, mas diferentemente do ouvido, que está concentrado em apenas dois pontos, o sentido do tato está espalhado pela maior parte da pele e mucosa. Os receptores destas diferentes sensações são chamados de corpúsculos sensitivos responsáveis pelas diversas associações como calor, leveza, frio, frescor, suavidade dentre outros nas quais não estão distribuídos uniformemente pelo nosso corpo. É importante salientar ainda que a sensibilidade está intimamente ligada ao contato, portanto objetos extremamente grandes ou distantes da pele são de difícil distinção (Martini, Timmons, \& Tallitsch, 2009)

Os corpúsculos sensitivos estão subdivididos em quatro categorias explicados brevemente neste trabalho, a. Corpúsculos de Meissner são responsáveis pelas impressões do contato se localizam na superfície da pele, principalmente em regiões como as palmas das mãos, dedos, lábios, margem da pálpebras, mamilos e genitália externa; b. Corpúsculo de Pacini ficam nas camadas mais profundas da pele e são responsáveis pelo estímulos de pressão e estão distribuídos em diferentes regiões do corpo; c. corpúsculos de Krause são responsáveis pelas sensações térmicas do frio e o d. Corpúsculo de Ruffini pela sensação térmica de calor, este dois últimos corpúsculos também estão distribuídos pelas diferentes partes do corpo (Martini et al., 2009). 


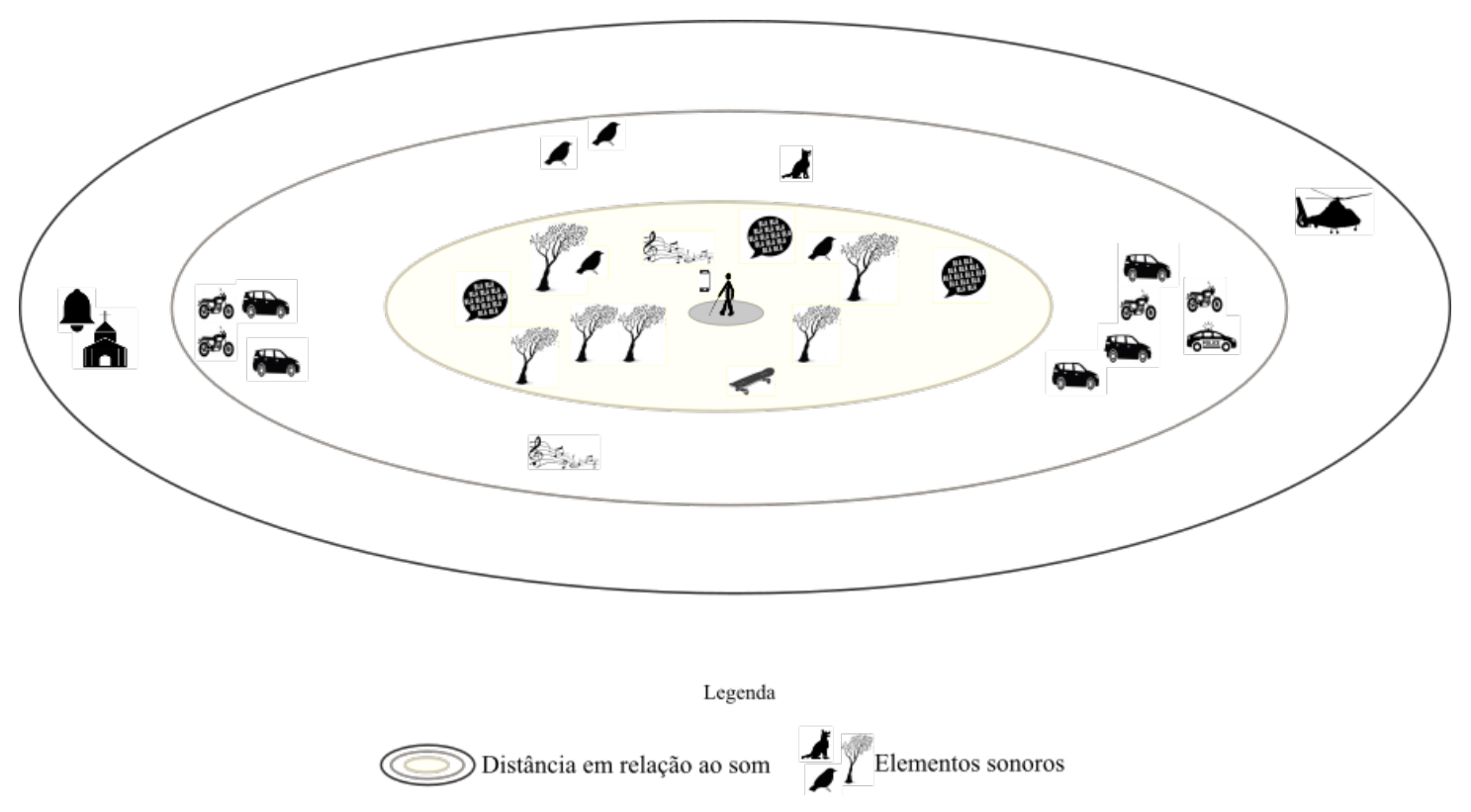

Figure 1. Paisagem Sonora - Dom Quixote dela Mancha

O tato desenvolvido nas palmas das mãos, associado aos movimentos finos, são os principais instrumentos utilizados pelos videntes para ter contato com os objetos e seres vivos, assim como os sujeitos cegos, que conseguem identificar diferentes características do resto de outras pessoas, diferentes formas da cidade, mesmo que seja um processo que leve um maior tempo quando comparado com a visão.

A importância dada ao tato o torna importante, principalmente, no sistema de educação em âmbito mundial com o desenvolvimento do sistema braile e também no âmbito brasileiro através da inclusão de crianças cegas utilizando maquetes e ou elementos que permitem uma compreensão da realidade por parte destes sujeitos sociais.

\section{Olfato e paladar}

As patologias sensoriais mais comumente conhecidas estão relacionadas aos setores da visão, da audição e da fala. Porém há várias patologias relacionadas ao paladar e ao olfato, variando entre níveis de acometimento, dos parciais aos integrais; incluindo também a deficiência táctil que ocorre de forma mais esporádica (PALHETA NETO, TARGINO, PEIXOTO, et al, 2011)

O olfato não necessita do toque direto para atender aos seus objetivos, absorve para si através do ar substâncias químicas que dele emanam, o que ocasiona uma alteração de sua percepção na medida em que 


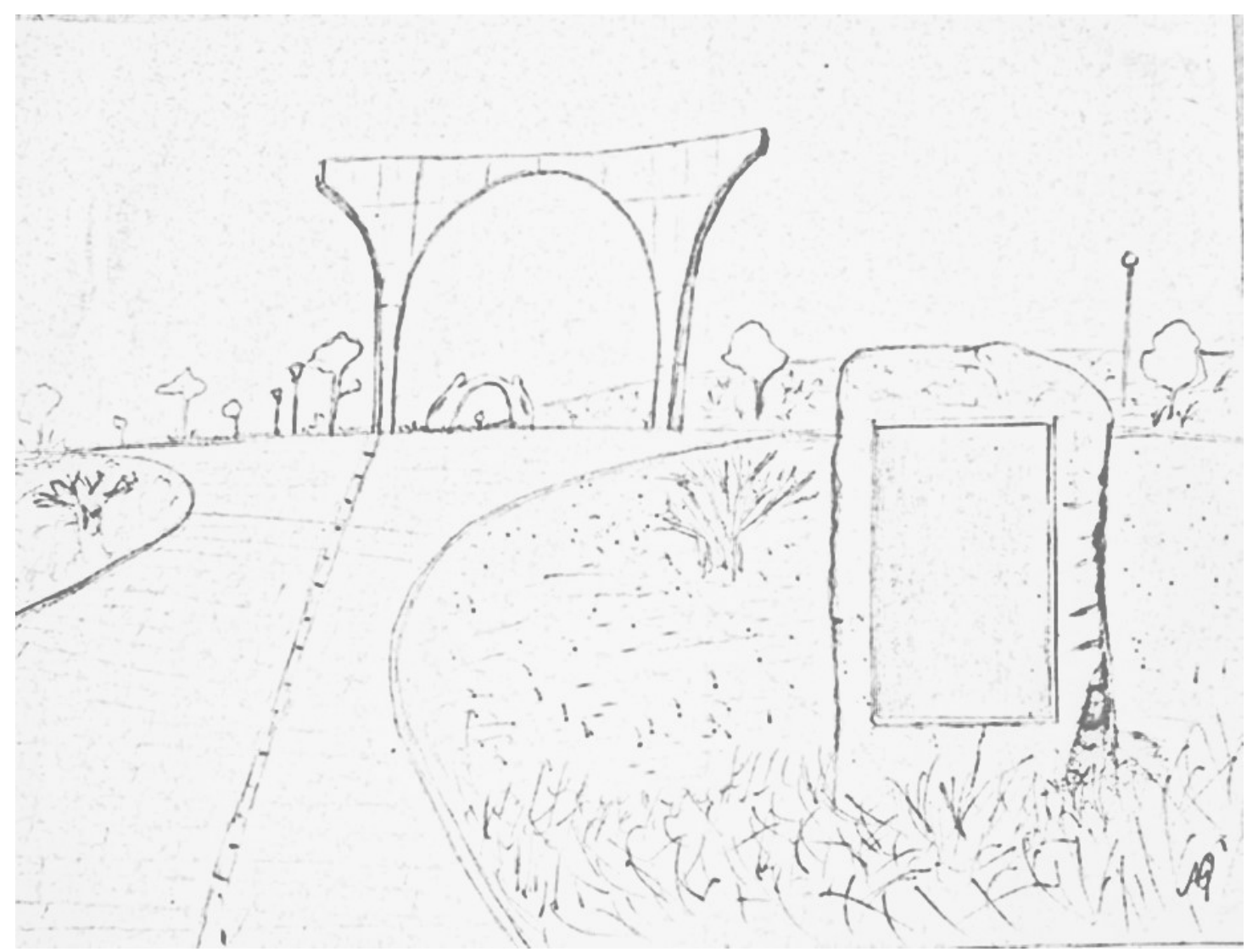

Figure 2. Croqui representando a paisagem

os objetos atingem o olfato e se afastam. Tal como o paladar, o olfato é um sentido químico. O mecanismo de percepção dos odores começa pelas células olfativas encontradas na região interna superior do nariz. A partir desse momento a informação olfativa é lançada no córtex cerebral integrando-se ao nosso material sensório-espacial (PALHETA NETO, TARGINO, PEIXOTO, et al, 2011).

O paladar é um sentido químico, tendo seus estímulos dos receptores gustativos atuando sobre as substâncias químicas dos alimentos. As papilas gustativas, são membranas estabelecidas na mucosa da boca, o gosto chega ao córtex primário. O paladar permite a uma pessoa selecionar substância a partir de seus próprios desejos e de acordo com as necessidades de cada metabolismo (Martini et al., 2009).

Nós seres humanos, o olfato é o sentido fisiologicamente menos desenvolvido. A vivência olfativa mostra-se, como no caso do paladar, intimamente entremeada com a esfera da sobrevivência: assim, os odores agradáveis são benéficos para o organismo e os desagradáveis são nocivos, isso acontece da mesma forma em relação aos sabores, sem contarmos que sentimos os odores ao mesmo tempo em que respiramos (PALHETA NETO, TARGINO, PEIXOTO, et al, 2011). 


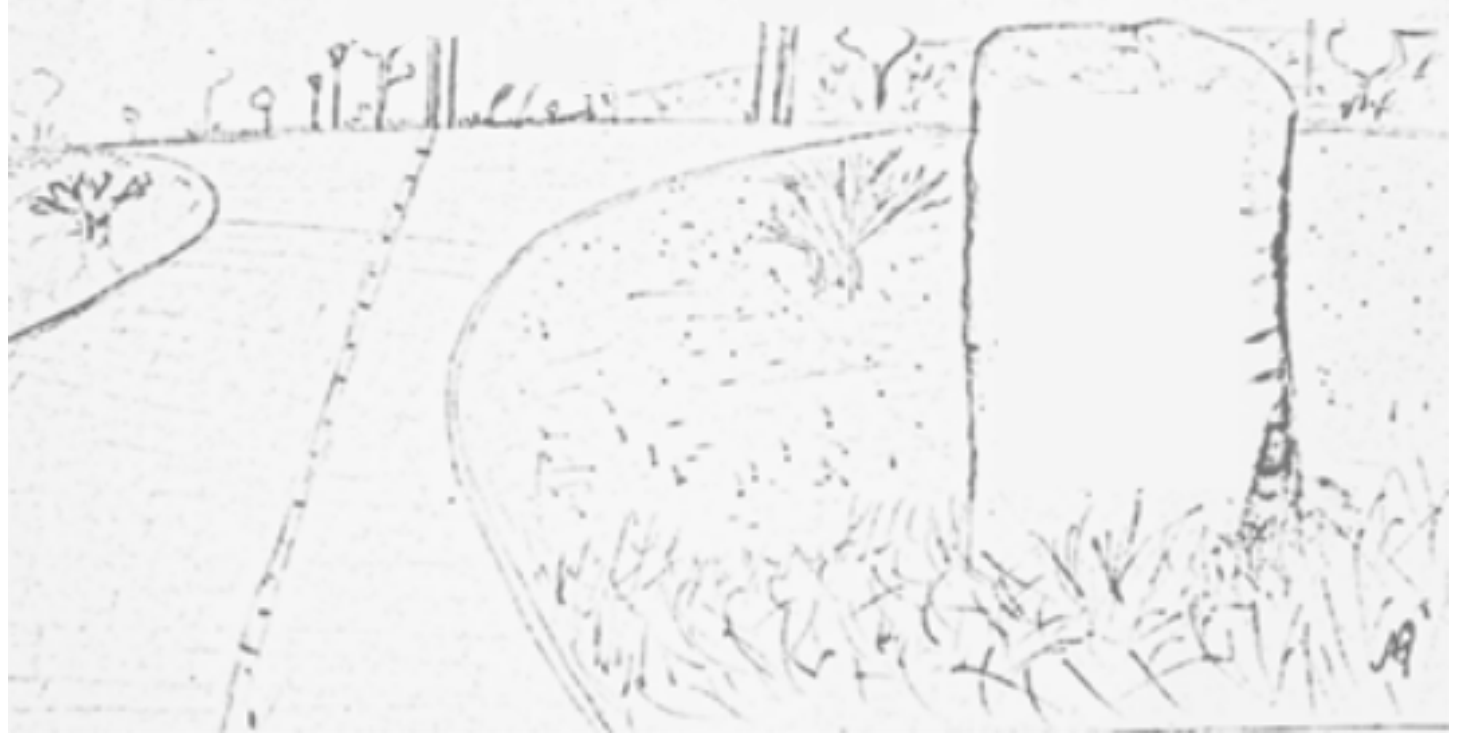

Figure 3. Croqui com manchas não perceptíveis aos cegos

Ao respirarmos, claramente executamos uma atividade vital para o organismo. Com pessoas cegas, a questão do olfato tende a desenhar uma função de maior importância, na dinâmica de orientação. Cotidianamente, cegos utilizam odores de diferentes lugares que circundam e caracterizam os ambientes.

Para elucidar como os sujeitos com cegueira constroem uma paisagem olfativa, criamos uma imagem a partir de uma atividade que realizamos com a Garota Dinamarquesa. Para execução desta tarefa andamos juntos por cerca de 500 metros em uma calçada. Durante este percurso ela foi descrevendo os cheiros e odores e apontando com o dedo de onde estava vindo essa percepção. A Garota dinamarquesa identificou três cheiros desagradáveis (Poluição dos automóveis, lixo urbano e esgoto) e dois agradáveis (perfume e comida).

Com o advento do desenvolvimento da sociedade e da tecnologia, novas formas de entender a realidade foram sendo incorporadas às pessoas com algum tipo de limitação como uso das lentes de grau no auxílio 


\section{Céu}

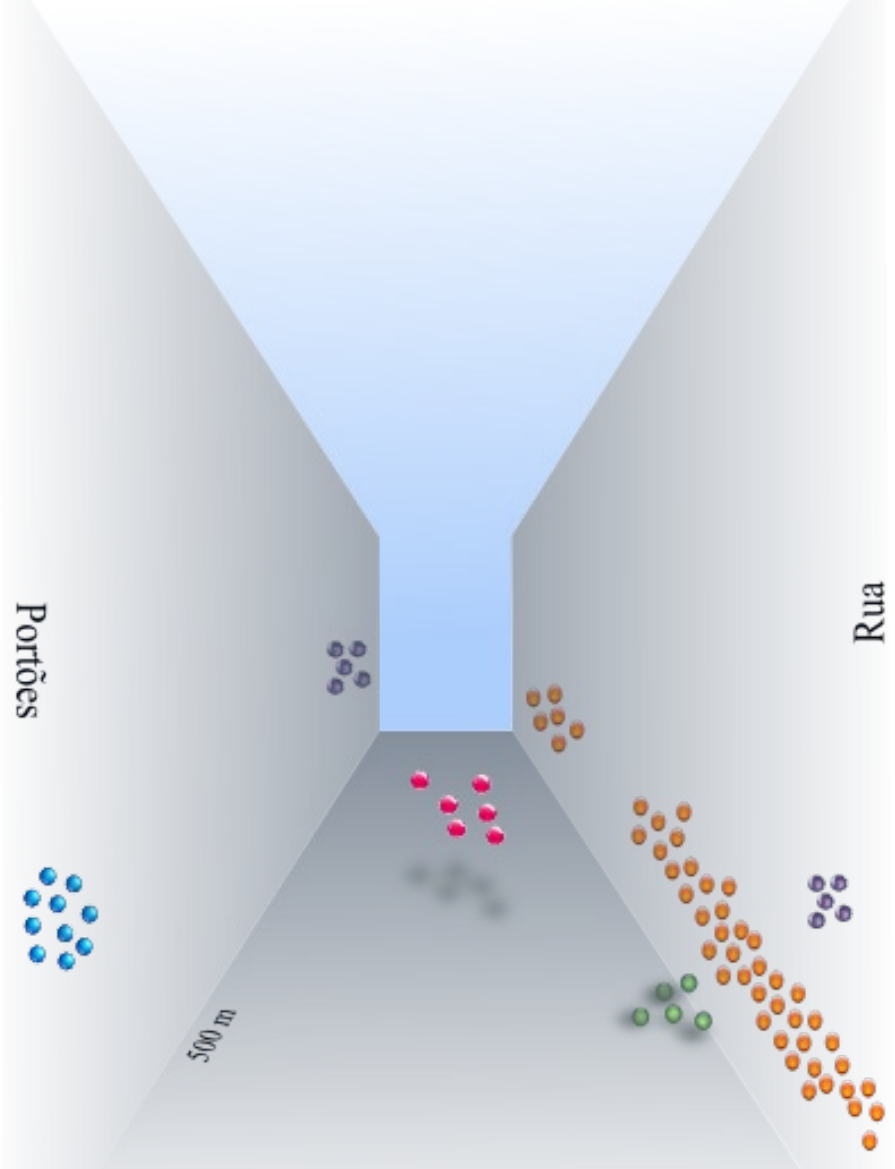

Calçada

Figure 4. Paisagem olfativa - A Garota dinamarquesa

\section{Cheiros da Rua}

- Poluição dos automoveís

- Lixo urbano

- Perfume

Esgoto

C Comidas 
da visão, pernas mecânicas e braços mecânicos, aparelhos auditivos, dentre outros. Com os sujeitoscom cegueira, isto também não foi diferente, principalmente com a chegada da bengala para cegos e uso de cão guia no auxílio do deslocamento de diversos ambientes.

A principal função da bengala é permitir uma maior segurança e velocidade para o sujeito cego caminhar, permitindo que os sujeitos detectem diversos níveis e objetos no plano do solo até sua cintura.

Essa extensão do corpo para entendimento da realidade pode se configurar muito além de auxílio, mas realizados.

também como sentido extra para o corpo e uma certa independência, principalmente nos trajetos

A bengala para cegos é um exemplo disto, pois possui diferentes formatos e tecnologias. Apesar do nome bengala para cegos, na verdade nada mais é que um bastão articulado que divide geralmente de quatro a sete partes iguais, com um tubo metálico formado por diferentes materiais dependendo do tipo de bengala e por dentro um fio elástico utilizado para dividir as partes da bengala sem desarticular uma parte da outra. Apesar das diferentes especificidades e diferentes materiais, as mais utilizadas são as bengalas de ponteiras fixas ou rotativas (MINISTÉRIO DA EDUCAÇÃO, 2006)

Juntamente com o aprimoramento da tecnologia, há cada vez mais a tentativa de incorporar tais práticas em bengalas para cegos, alguns tipos destas bengalas já estão disponíveis. A mais utilizada é a que emite um sinal sonoro quando a ponta da bengala, que está em contato com chão, encontra um obstáculo à sua frente.

Para a utilização da bengala, devem ser feitos cursos técnicos pois diversos fatores precisam ser considerados, como o tamanho da bengala (o tamanho auxilia na coordenação pé/bengala ou toque/passada e sua altura deve estar alinhada ao diafragma); movimentação (descolar a bengala ao pé oposto em movimento, o movimento de pêndulo deve cobrir toda a largura do corpo e a bengala deve estar ao sentido oposto ao pé que está à frente no passo e estar com o dedo indicar acompanhando a bengala como se fosse a extensão do corpo), (Brasil, 2003).

Esses cursos, geralmente, são oferecidos por associações, instituições ou organizações presentes nas cidades, como a associação de proteção aos cegos na cidade de Presidente Prudente/SP e Laramara e Adorino Novil na cidade de São Paulo/SP, que oferecem tudo de forma gratuita. A introdução e as técnicas de uso da bengala longa são apresentadas para a pessoa cega nos treinamentos de Orientação e Mobilidade (OM) (Brasil, 2003).

Outros dispositivos vêm sendo testados em laboratório, como o sistema de substituição tátil-visual (TVSS), que tem por finalidade transformar estímulos visuais em estímulos elétricos compostos por uma câmera que capta o sinal visual, um computador, um conversor que transforma energia luminosa em energia elétrica e uma matriz de estimulação elétrica na pele. Esses estímulos na pele geram padrões e, com o tempo, serão responsáveis pela formação de uma imagem tátil distal.

Os ciborgues da vida real, como denomina Bach-Y-Rita (2002, p.953), sofrem alterações

“[...] por meio de incorporação de marcadores softwares leitores de tela, ou quaisquer outros recursos ou acoplamentos criativamente desenvolvidos em práticas cotidianas, nas relações que se estabelece em um ambiente, estão ativamente reescrevendo os textos de seus corpos e sociedades

Bach-Y-Rita (2002, p.953)

Contudo, ao mesmo tempo que devemos pensar como formar alternativas que lidam de certa forma com a ausência da visão, carrega consigo um estigma social que indica que o portador de tais aparelhos é um 
indivíduo cego e também perigoso relacionados aos riscos a violência de assaltos, por serem considerados pela sociedade como vulneráveis.

Essa rejeição ocorre principalmente na fase de aceitação da cegueira que muitas pessoas tentam esconder a sua limitação ou provar para as outras pessoas que a cegueira não mudou nada na sua relação com o ambiente. Esse processo deve ter uma atenção maior por parte da sociedade para o acolhimento, inclusão e ressignificação de suas práticas.

Lugli e Okimoto (2016) salientam que para evitar a rejeição de sujeitos que já nascem cegos, é indicado que desde de pequeno a criança tenha contato com atividades que são denominadas de prébengala, no qual nada mais é que a utilização de objetivos que como cadeiras, carrinhos de bonecas, carrinho de feira, bastões que auxiliem a manipulação e compreensão a respeito da utilização da bengala.

Além da utilização de tecnologias, o sujeito com cegueira pode optar pela utilização de elementos vivos, como o caso do cão guia, que ainda não apresenta uma grande adesão no Brasil, tendo em vista a falta de lugares especializados no treinamento destes animais e pelo alto custo associado.

A Lei $n^{\circ} 11.126 / 2005$ garante o ingresso do cão guia que em locais públicos ou privados com o fim exclusivo de guiar a pessoa com cegueira que deve seguir alguns requisitos como estar castrado, não ser um animal agressivo, ter porte adequado para a realização da sua função e estar com vacinação completa. A proibição do ingresso do cão-guia é justificada em estabelecimento de saúde e lugares esterilizados. Exceto esses lugares a proibição de pessoas cegas de frequentar lugares por estar com o cão-guia constitui ato de discriminação, sendo penalizado com multa e até interdição do local (Souza \& Ferreira,2018).

O treinamento de cão-guia é um processo complexo e pode chegar a até dois anos, mesmo período que deve ser o treinamento para sujeitos cegos, que deve seguir as seguintes etapas: seleção de animais compatíveis para a finalidade, socialização, treinamento específico para a função e adaptação do cão junto com a pessoa com deficiência. Muitos cachorros podem ser desligados de tais práticas pelo comportamento do animal, o que pode atrasar o processo para aquisição de cão-guia. Diferente do uso das bengalas, os cães-guias são elementos fundamentais na aproximação das pessoas cegas com os outros sujeitos, na medida que cachorros fazem parte da vida diária das pessoas (Souza \& Ferreira,2018).

\section{Uma construção mental da cidade a partir do lugar}

Podemos perceber desde o início deste artigo, o tempo, as interseccionalidades, o movimento e os sentidos do corpo e os próprios elementos urbanos da cidade, juntos, vão produzindo uma maneira particular de cada sujeito construir um mapa mental da cidade. É claro que esta construção mental privilegia alguns locais em detrimento de outros a partir das variáveis já citadas.

Para as pessoas com cegueira terem um mapa mental é extremamente necessário conseguir se localizar na cidade, necessidades e afazeres do dia-a-dia e até mesmo uma independência das pessoas para realizar determinadas atividades.

Construir um mapa mental para estes sujeitos é muito desafiador, porque para as pessoas que enxergam, quase cem por cento das respostas é baseada na visão, principalmente para memorizar locais, trajetos, pontos de referências. Para quem perdeu a visão ainda tem uma memória dos antigos trajetos e lugares, contudo, ainda assim é difícil acompanhar todas as transformações da cidade.

Pude perceber durante a realização da pesquisa que, além dos sentidos do corpo auxiliarem no processo de construção de uma memória espacial, os lugares de pertencimento também constroem esta percepção, pois quanto mais afeto sentimos dos diferentes ambientes, maior a tendência de voltarmos a esse lugar. 
Ao se movimentar de um lugar de pertencimento a outro, vão se criando uma memória dos trajetos, auxiliando os sentidos de direções que afloram (direita, esquerda, para frente e para trás) e os sentidos do corpo como o olfato (o cheiro de bolacha que vem de uma fábrica), o paladar (a comida de vó), a audição (diversos sons da cidade, relatos de outras pessoas), o tato (muro chapiscado, uso de bengala que distingue diferentes tipos de chão, buracos na rua, pisos acessíveis e até as partes da calçadas levantadas pelas raízes das árvores).

A construção mental da cidade é, portanto, realidade e imaginação, é a descoberta do novo a cada dia, se surpreender e se alegrar com novos elementos e se entristecer com coisas que nunca mudam, são pequenos detalhes que fazem as pessoas ter uma memória da cidade para chamar de sua.

\section{Conclusão}

Baseando nos conhecimentos adquiridos a partir da pesquisa podemos compreender que a visão é o principal sentido utilizado pelos seres humanos, consequentemente a sua ausência faz que sujeitos criem capacidade através dos desenvolvimentos dos outros sentidos uma própria percepção da cidade, uma cidade imagina através do tato, paladar, cheiro, audição.

Os três sujeitos, cada qual com seus particulares, encontraram alternativas para lidar com as limitações impostas pela vida e que puderam ser cartografadas neste artigo. Contudo, é necessário ressaltar que o desenvolvimento do corpo para lidar com as adversidades não deve ser desculpa para falta de políticas públicas e na busca por equidade dentro do espaço urbano e na sociedade.

\section{Referências}

Bach-Y-Rita, P.(2002). Sensory substitution and qualia (Noë, A. Thompson, \& Evan, Eds.). Cambridge, MA: MIT Press.

Brasil. (2003). Orientação e mobilidade: conhecimentos básicos para a inclusão do deficiente visual (E. de Edileine Vieira Machado et al. Brasília: MEC/SEESP, Ed.).

Brasil. (2012). Retrieved from http://www.planalto.gov.br/ccivil_03/_ato2004 -2006/2005/Lei/L11126.htm.Acessoem:09/02/2012

Lugli, D., Suemitsu, K., Minozzo, M., \& Okimoto, M. L. (2016). Bengala customizável para mulheres com deficiência visual. Design e Tecnologia, 6(12), 44-53.

Martini, F., Timmons, M. J., \& Tallitsch, R. B. (2009).

Neto, P., Targino, F., Peixoto, M. N., Alcântara, V. P., Jesus, F. B., De, C., ... De, E. (2011). Anormalidades sensoriais: olfato e paladar. Arquivos Int. Otorrinolaringol. (Impr(3), 15-15.

Schafer, R. M. (1992).

Souza, M., \& Ferreira, L. A. (2018). A tecnologia assistiva cães-guia no brasil: uma ação do programa viver sem limite. Revista Observatório(3), 4-4. 